\title{
EDUCAÇÃO, APRENDIZAGEM E TECNOLOGIA NA PESQUISA-FORMAÇÃO
}

\author{
FANTIN, Monica ${ }^{1^{*}}$ \\ ${ }^{1}$ Universidade Federal de Santa Catarina \\ mfantin@terra.com.br*
}

\section{RESUMO}

A integração significativa das tecnologias digitais nos processos de ensino-aprendizagem tem assumido papel de destaque entre os desafios da educação contemporânea. Práticas diferenciadas na formação universitária e diferentes experiências de investigação na perspectiva da mídia-educação destacam uma abordagem da pesquisa-formação - com ênfase num trabalho colaborativo entre professores, estudantes e pesquisadores -, que propicia diferentes formas de diálogo com o território. É no contexto dessas experiências e relações que o artigo reflete sobre a tecnologia como cultura, mediando os processos de ensino-aprendizagem na formação universitária e continuada com professores a partir de experiências de pesquisa-formação desenvolvidas em diferentes investigações e contextos socioculturais.

PALAVRAS-CHAVE: Ensino-aprendizagem. Formação com professores. Pesquisa-formação. Cultura digital.

\section{EDUCATION, LEARNING AND TECHNOLOGY IN THE RESEARCH-DEVELOPMENT}

\begin{abstract}
The significant integration of digital technologies into teaching-learning processes has assumed a prominent role among the challenges of contemporary education. Differentiated practices in university education and different research experiences from a media-education perspective highlight a research-training approach - with emphasis on collaborative work among teachers,

students and researchers -, that provides different forms of dialogue with the territory. It is in the context of these experiences and relationships that the article reflects on technology as a culture mediating the teaching-learning processes in university education and continued with teachers from research-training experiences developed in different investigations and sociocultural contexts.
\end{abstract} KEYWORDS: Teaching-learning. Teacher training. Research-development. Digital culture.

\section{EDUCACIÓN, APRENDIZAJE Y TECNOLOGÍA EN LA INVESTIGACIÓN-FORMACIÓN}

\section{RESUMEN}

La integración significativa de las tecnologías digitales en los procesos de enseñanza-aprendizaje ha asumido un papel destacado entre los desafíos de la educación contemporánea. Las prácticas diferenciadas en la formación universitaria y diferentes experiencias de investigación en la perspectiva de los medios de comunicación destacan un enfoque de la investigaciónformación - con énfasis en un trabajo colaborativo entre profesores, estudiantes e investigadores -, que propicia diferentes formas de diálogo con el territorio. Es en el contexto de estas experiencias y relaciones que el artículo refleja sobre la tecnología como cultura mediando los procesos de enseñanza-aprendizaje en la formación universitaria y continuada con profesores a partir de experiencias de investigación-formación desarrolladas en diferentes investigaciones y contextos socioculturales.

PALABRAS CLAVE: Enseñanza-aprendizaje. Formación con profesores. Investigación-formación. Cultura digital. 


\section{INTRODUÇÃO}

Crianças e jovens produzem conhecimentos os mais diversos, interagindo direta ou indiretamente com os pares, com a tecnologia e com as inúmeras produções culturais nos mais diferentes cenários da cultura. Essas interações presenciais ou on-line que as redes sociais da internet propiciam devem ser pensadas na escola a partir de novas sociabilidades, autorias e possibilidades colaborativas de construção de conhecimento que permitem novos modos de ser e perceber o mundo.

As ferramentas da cultura digital têm modificado as práticas individuais e sociais de crianças, jovens e adultos que interagem com as tecnologias digitais, construindo múltiplas redes que solicitam um papel ativo, cada vez menos simples leitor e cada vez mais autor de seus conteúdos, interpelando os que atuam com educação. A mobilidade/portabilidade e a conectividade, ao permitirem maior autonomia em relação aos consumos midiáticos, também promovem outros tipos de práticas culturais e de consumo que precisam ser discutidas e mediadas nos contextos formativos.

Se, em relação às mídias tradicionais, o problema que se colocava à educação era o da abordagem crítica no sentido de evitar o consumo passivo, a questão que se coloca é a de educar não só para o consumo crítico, criativo e responsável, mas, sobretudo, para uma produção responsável do ponto de vista ético-estético na perspectiva de uma cidadania digital.

Diante do mapa da exclusão digital no Brasil (NERI, 2013), ainda são inúmeras as desigualdades que separam os excluídos do acesso às tecnologias, e tal fato requer uma mediação cultural na perspectiva da inclusão digital que transcenda os limites utilitaristas e o acesso meramente operacional às máquinas e aos programas. Enfatizamos uma inclusão que signifique qualidade do acesso e que seja também social, política e cultural, o que necessita mediações pedagógicas (FANTIN; GIRARDELLO, 2009). Tais mediações ancoram-se na perspectiva da mídia-educação, que envolve o educar para/sobre as mídias, com as mídias e através das mídias, a partir de um viés crítico, instrumental e produtivo-expressivo (FANTIN, 2006).

A adoção de uma postura "crítica e criadora" de capacidades comunicativas, expressivas e relacionais é fundamental para avaliar ética e esteticamente o que está sendo oferecido, produzido e compartilhado pelas mídias e redes, de modo a educar para a cidadania (BELLONI,

Educação \& Formação, Fortaleza, v. 2, n. 6, p. 87-100, set./dez. 2017

DOI: http://dx.doi.org/10.25053/edufor.v2i6.2377

http://seer.uece.br/redufor 
2010). A questão que se coloca hoje não é apenas a respeito do uso das Tecnologias da Informação e Comunicação (TIC) ou do "letramento digital", mas de tal uso em uma vertente transformadora e um entendimento das tecnologias e das mídias como cultura, como propõem Bonilla e Fantin (2015), em um contexto de aprendizagens situadas.

Diante da complexidade que envolve o conceito de aprendizagem no contexto da cultura digital, como ponto de partida utilizaremos uma definição que, segundo Santaella (2014), está pouco sujeita a controvérsias e nos permite entender a questão da aprendizagem no contexto da cultura digital. "O conhecimento é uma mistura fluida de experiência emoldurada, valores, informação contextual e insight experto que fornece uma moldura para avaliar e incorporar novas experiências e informações" (DAVENPORT; PRUSAK, 1998 apud LIAW; HATALA; HUANG, 2010, p. 447). Se considerarmos que não existe conhecimento sem aprendizagem, no contexto da cultura digital o processo de aprendizagem envolve encontrar, recuperar e produzir conhecimento a partir da interação com diversos ambientes de aprendizagem que intensificam a reelaboração de conhecimentos propiciados pelas redes digitais (BARKER, 2005 apud LIAW; HATALA; HUANG, 2010).

Para pensar o sentido da aprendizagem além das redes, uma reflexão que pode contribuir com tal entendimento é a noção do dispositivo da previsão: "Boa parte (senão tudo) daquilo que habitualmente chamamos aprendizagem tem a ver com a nossa capacidade de prever comportamentos das coisas e dos outros ao nosso redor e também conosco" (RIVOLTELLA, 2014, p. 5). Com paráfrase de Descartes, para o autor, saber se reduz a prever, pois a previsão é a base da simulação, "[...] daquele dispositivo didático que permite àquele que aprende imaginar quais consequências produzidas na manipulação das variáveis que regulam o comportamento de um fenômeno" (RIVOLTELLA, 2014, p. 5).

Com base na noção de previsão, podemos construir um entendimento do processo educativo "[...] na ótica de uma verdadeira semiótica do espaço, saber ler os sintomas nas faces, nos olhares, nas dinâmicas, significa imaginar o que poderia acontecer e agir em consequência disso" (RIVOLTELLA, 2014, p. 5-6). Essa ideia da aprendizagem como uma capacidade de previsão tem ressonância em alguns mecanismos da pesquisa neurocientífica que evidenciam e explicam no plano experimental o que a filosofia e as ciências humanas há tempo vêm intuindo (RIVOLTELLA, 2014). 
Nesse quadro, a construção de novos entendimentos sobre o processo de aprendizagem por meio do qual a complexa realidade sociocultural nos desafia, as estratégias para integrar os usos das tecnologias e seus dispositivos na didática têm solicitado um trabalho com competências específicas que interpelam a didática quanto a diferentes abordagens sobre novos modelos e modalidades operativas do processo de ensino-aprendizagem. Entre esses modelos, surge o conceito de Episódios de Aprendizagem Situada (EAS), que se origina na reflexão sobre mobile learning e nas atividades de microlearning que foram impulsionadas pela cultura digital. $\mathrm{O}$ microlearning é "[...] um processo de aprendizagem informal relacionado aos fenômenos que atravessam as culturas de mídias atuais, suas fragmentações e recombinações de formatos textuais e transmidiáticos" (RIVOLTELLA, 2013, p. 51-52).

Desse modo, a metodologia dos EAS é também uma proposta de integração dos dispositivos móveis na didática e fundamenta-se em quatro ideias-chave: o ensino como design, o aprender fazendo, a flipped teaching e a interseção entre neurociência e didática (FANTIN, 2015a; RIVOLTELLA, 2015). Sua estrutura prevê uma organização do encontro pedagógico a partir de três momentos: momento prévio: um quadro conceitual ou uma situação-estímulo que encaminha uma atividade preparatória aos alunos; momento operativo: uma microatividade de produção em que o aluno deve resolver um problema ou produzir algum conteúdo sobre a situação-estímulo; momento reestruturador: um debriefing sobre o que aconteceu nos momentos anteriores, com retorno sobre os processos ativados e conceitos que emergiram de modo a refletir aspectos a serem salientados (RIVOLTELLA, 2013).

Esses momentos articulam-se com design, ações didáticas e tipos de aprendizagem, que, por sua vez, envolvem as ações dos estudantes e suas estratégias de aprendizagem. No campo da aprendizagem situada, destacamos as ações dos estudantes (fazer tarefas; ler; comunicar-se; entender; produzir e compartilhar; analisar, discutir e refletir sobre os processos desencadeados) e suas estratégias de aprendizagem (a resolução de problemas, o aprender fazendo e a aprendizagem reflexiva). Esses processos se constroem de forma orgânica na perspectiva da inseparabilidade entre ensino-aprendizagem. E tais processos se constroem por aquisição, por pesquisa, por colaboração e por discussão e envolvem ações didáticas voltadas ao fazer experiência, conceitualizar, analisar, aplicar, discutir e compartilhar.

Educação \& Formação, Fortaleza, v. 2, n. 6, p. 87-100, set./dez. 2017 
Tais práticas dependem sempre de mediações ou de "mediadores didáticos", como, por exemplo, os propostos por Damiano (2013) em sua teoria de ensino como mediação, em que o autor sugere a importância dos mediadores ativos, icônicos, analógicos, simbólicos e didáticos, que, por seu turno, se aproximam da perspectiva das multiliteracies.

\section{MULTILITERACIES NA FORMAÇÃO UNIVERSITÁRIA: OFICINAS DE PRODUÇÃO E REFLEXÃO}

A apropriação das tecnologias no contexto da cultura digital hoje envolve a construção de conhecimentos em diferentes linguagens (escrita, plástica, musical, audiovisual, digital), que possuem seus códigos e especificidades. Por sua vez, seus processos de aprendizagem são complexos e envolvem conceitos e dimensões que se entrecruzam numa perspectiva de múltiplas linguagens e multiliteracies (COPE; KALANTZIS, 2000).

O conceito de multimedia literacy hoje envolve a media literacy, a digital literacy e a informational literacy e pode ser visto como uma das múltiplas literacias requeridas pelas mídias contemporâneas (BUCKINGHAM, 2005, 2008; FANTIN, 2010; RIVOLTELLA, 2013). Assim, mais do que uma inclusão da mídia-educação, da digital literacy ou da multimedia literacy "substituindo" em alguma medida os conteúdos da "tecnologia educacional" nos currículos dos cursos de formação de professores, é interessante pensar também em uma abordagem transversal no currículo que atravesse diversos âmbitos das disciplinas e das práticas de formação.

O conceito de media literacy e multimedia literacy envolve diversas áreas emergentes e termos, como visual literacy, media literacy, critical literacy, informational literacy e technology literacy, ampliando o conceito de literacy em suas formas de expressão e comunicação visual, eletrônica e digital, incluindo seus respectivos objetos de estudo e análise. Para tal, é necessária a construção de certas competências que requerem mudanças no meio ambiente de aprendizagens, bem como nos sistemas de ensino como um todo: o currículo, a avaliação, os projetos, o acesso às tecnologias e suas conexões em rede, a arquitetura escolar, as formas de mediação, etc.

Nesse processo de ensino-aprendizagem, as multiliteracies intercruzam a arte, a ciência, a narrativa e o lúdico como linguagens fundamentais em que o sujeito expressa e comunica seus sentimentos, suas ideias e experiências das mais diversas formas: orais, escritas, plásticas, corporais, musicais, eletrônicas, audiovisuais e digitais. Se cada linguagem possui suas formas de 
expressão, o professor precisa aprender a utilizar os diversos tipos de mídia e aprender seus diferentes modos de ensinar, expressar, informar, persuadir e também divertir. Isso exige uma formação de professores que lide com a expressão e criação não só a partir do conhecimento científico, mas também como possibilidade de formação estética.

De acordo com tais propósitos, construímos uma experiência num curso de Pedagogia de uma universidade federal, desenvolvida entre 2012 e 2015, no interior de diversas disciplinas, de modo a articular seu objeto de estudo com a dimensão das multiliteracies. O ponto de partida era uma fundamentação teórico-metodológica sobre mídia-educação de forma articulada aos conteúdos disciplinares, envolvendo também o trabalho com oficinas e enfatizando as múltiplas linguagens, sobretudo as linguagens das mídias.

O trabalho visava propiciar a produção de expressão de conhecimentos dos estudantes a partir das vivências das múltiplas linguagens. Considerando as formas em que as crianças e os adolescentes se expressam, as oficinas buscavam oferecer instrumentos teórico-práticos para problematizar certas linguagens utilizadas na escola, no sentido de provocar e abrir caminhos para ampliar seus saberes e fazeres, que não se localizam apenas na dimensão puramente cognitiva e conceitual nem se situam na dimensão sensível do "fazer pelo fazer". Assim, com base nas vivências propostas nas diferentes linguagens, a construção de experiências articulava-se com um aspecto considerado central da docência e do "ser professor", que é o trabalho com a criação, através de situações que envolvem ensino-aprendizagem, observação, descoberta, experimentação, estranhamento, curiosidade, razão e sensibilidade.

Conhecer as possibilidades de uso pedagógico das tecnologias móveis é fundamental para uma educação que pretende educar com, sobre e através das mídias e numa perspectiva ecológica de mídia-educação e do mobile learning (PACHLER, 2007). Nas oficinas, as dimensões crítica, instrumental e produtiva da mídia-educação articulavam-se aos estudos e práticas a respeito da produção de audiovisual, fotografia, cinema, jornal escolar, pesquisa em rede, uso e produção de blogs, interação nas redes sociais, etc.

No contexto da referida disciplina, as oficinas eram entendidas como uma possibilidade de promover situações que enfatizavam a circulação de saberes e a construção de autorias num percurso que envolvia as estratégias de aprendizagem de resolução de problemas, o aprender 
fazendo e a aprendizagem reflexiva. Nesse sentido, as oficinas trabalharam com princípios educativos de aprendizagem, uso, apropriação, expressão e reflexão.

Essa perspectiva de trabalho com oficinas atualiza o pensamento de Freinet (2002, p. 167), um educador muito contemporâneo em seu tempo, ao enfatizar que "[...] cada época tem a sua linguagem e os seus instrumentos". Por exemplo, as correspondências escolares não só ultrapassavam as fronteiras da escola como anunciavam novas formas de interação e participação das crianças na cultura, e tais práticas modernas implicaram muitas orientações pedagógicas que hoje fundamentam certas práticas mídia-educativas. Assim, ao atualizar tal perspectiva no trabalho com as oficinas, como sugere Fantin (2012), foi possível reafirmar a importância de minimizar as rupturas entre os momentos da aprendizagem das múltiplas linguagens - das múltiplas alfabetizações e letramentos e suas aprendizagens práticas, científicas, literárias, artísticas, audiovisuais, multimídias - e os momentos de apropriação das competências adquiridas e construídas individual e coletivamente.

Nesse sentido, a ideia do trabalho coletivo observada na proposta das oficinas é ampliada com o conceito da sala de aula como "comunidade de aprendizagem" proposto por Bruner (2002). Para ele, uma das propostas mais radicais da psicologia cultural no campo da educação é a que revoluciona a concepção de sala de aula, “[...] considerando-a uma subcomunidade de pessoas que aprendem uma com a outra, onde o docente tem a tarefa de orquestração" (BRUNER, 2002, p. 35). Essa subcomunidade não diminui o papel nem a autoridade do professor, que tem a tarefa de compartilhar com os outros o seu papel. Em tal perspectiva, a sala de aula é vista como um laboratório, um lugar de aprendizagens e de trabalho que se pretende cooperativo, mais do que colaborativo.

Os valores destacados acima sugerem que essa forma de entender a educação para as múltiplas linguagens pode significar um convite à reflexão e à criação de cultura, pois "[...] ela deve expressar atitude e deve convidar a uma contra-atitude e, durante este processo, deixar lugar para a reflexão, para a metacognição. É isso que permite que se alcance um patamar mais elevado" (BRUNER, 1998, p. 135). Assim, a possibilidade de estudantes se apropriarem da palavra e das imagens em movimento é um processo que pode ser ampliado com as múltiplas linguagens nos espaços de oficinas que fazem parte da formação inicial, e isso permitiu a construção de outras narrativas nas práticas educativas (FANTIN, 2012). Permitiu também pensar propostas 
pedagógicas na escola, considerando outras formas de fazer, refletir e representar como momentos fundamentais de um processo de ensino-aprendizagem que pretende articular ciência, arte, comunicação e cultura na formação universitária de professores. Além disso, tal experiência propiciou importantes reflexões que também se articulam com uma pesquisa-formação.

\section{PESQUISA-FORMAÇÃO NA ESCOLA}

A ideia de encorajar os professores da escola a se envolverem nos processos de pesquisa é cada vez mais recorrente, sobretudo porque supõe que a participação nos processos investigativos possa melhorar suas práticas pedagógicas (LONGAREZI; SILVA, 2008).

Diversas experiências de pesquisa sugerem outras possibilidades de fazer ciência da educação, pois, mais do que constatar os problemas da escola e dos professores, o pesquisador busca trabalhar a formação com eles, de modo a discutir certas práticas para atuar de forma conjunta na resolução de problemas identificados. Próxima dos pressupostos da pesquisa-ação, tal perspectiva de investigação questiona a neutralidade do pesquisador e considera que apenas a pesquisa reativa não é suficiente, sobretudo em nosso contexto, sempre tão precário e sedento de alternativas (FANTIN; QUARTIERO, 2015; QUARTIERO; FANTIN, 2014).

Ao romper com a ideia de que professores e estudantes são apenas objetos da investigação, essa perspectiva considera-os sujeitos e parceiros da pesquisa e formação. Nesse processo, o diálogo entre pesquisador e docente é constantemente incentivado e as devoluções parciais sobre a construção dos dados de pesquisa decorrem do processo investigativo, que também pode se configurar como formação continuada.

Tal prática tem sido denominada como pesquisa-formação (LONGAREZI; SILVA, 2008) e implica tanto a produção do conhecimento quanto a transformação da realidade mediante a solução de problemas teóricos e/ou práticos ancorados no cotidiano. E a formação continuada com professores é desenvolvida no contexto dessa relação, que tem na prática pedagógica o conteúdo dos processos formativos.

Nesse processo investigativo-formativo, os professores e pesquisadores pretendem compreender a realidade e complexidade do processo educativo e também compartilhar atividades formativas na escola com vistas a intervir nessa realidade. Tal intervenção pode "[...]

Educação \& Formação, Fortaleza, v. 2, n. 6, p. 87-100, set./dez. 2017

DOI: http://dx.doi.org/10.25053/edufor.v2i6.2377

http://seer.uece.br/redufor 
viabilizar mudanças significativas para uma transformação qualitativa da sua realidade, principalmente na sala de aula, que é o seu universo de referência no sistema educacional" (LONGAREZI; SILVA, 2008, p. 4056).

No contexto francês, concepção semelhante foi desenvolvida por Durand, Saury e Veyrunes (2005) com o objetivo de articular os resultados da pesquisa em educação com as práticas de formação docente. Para eles, as dificuldades nesse processo envolvem certa oposição entre uma "epistemologia dos saberes" e uma "epistemologia da ação". Os contrastes entre tais epistemologias revelam questões sobre o exercício profissional e a formação de professores, bem como suas relações com a pesquisa e seus resultados. Segundo os autores, a assimetria das dificuldades observadas nessas duas epistemologias pode ser minimizada diante da análise e do envolvimento nas atividades durante a pesquisa, visto que, na maioria das vezes, tais dificuldades são "invisíveis" nessas abordagens.

Para professores e pesquisadores que atuam com pesquisa e formação inicial, a escola é considerada um campo privilegiado que permite unir ensino, pesquisa e extensão, sobretudo construir possibilidades de parceria entre universidade e território, ao enriquecer as potencialidades da investigação e do ensino. É o que demonstram diversas pesquisas nessa perspectiva, ainda que nem sempre se denominem como pesquisa-formação.

No entanto, entre tantas dificuldades presentes nesse processo de pesquisa-formação, uma particularmente diz respeito ao distanciamento para as análises. Tal fator complicador pode ser minimizado com a reflexão constante sobre as especificidades de tais processos, e isso pode ser observado em diversas pesquisas que atuaram nessa perspectiva: em uma pesquisa que viabilizou um grupo de estudos em mídia-educação com professores durante a investigação (FANTIN, 2012); nas propostas formativas com professores na escola durante o desenvolvimento de uma pesquisa sobre o uso de tecnologias móveis na escola (FANTIN; QUARTIERO, 2015); na proposta de um curso piloto de formação com professores sobre uma nova metodologia de integração das tecnologias na didática, como um output da pesquisa, que teve os professores como parceiros (FANTIN, 2016). Na primeira, como resultado do trabalho do grupo, foi elaborada uma proposta para pensar a formação de professores na vertente da mídia-educação a partir de olhares dos docentes das escolas, dos educadores que atuam com formação continuada e dos professores-pesquisadores que atuam com formação universitária (GUNTZEL et al., 2012). Na 
segunda, os professores participaram da formação, juntamente com alunos-monitores, inovando ao estabelecer um diálogo baseado nas possibilidades de reconhecimento do trânsito de saberes formais e informais (FANTIN, 2015b). Na terceira, a partir do processo formativo desencadeado no curso piloto, os professores que participaram da pesquisa puderam compartilhar suas experiências formativas no seminário de socialização da pesquisa de forma a assegurar outras formas de participação no território com base no diálogo e parceria entre universidade e escola (FANTIN, 2016), processo sobre o qual discutiremos a seguir.

\section{O TRABALHO COLABORATIVO NA PESQUISA-FORMAÇÃO COM PROFESSORES}

Como desdobramento de abordagens de pesquisa-formação, vale destacar duas experiências em que o protagonismo dos professores se construiu no processo de investigação.

Na pesquisa sobre os usos das mídias e consumos culturais na formação de professores, pretendíamos aprofundar reflexões sobre as dificuldades encontradas e as boas práticas desenvolvidas pelos docentes na perspectiva da mídia-educação (FANTIN, 2012). A partir de um estudo longitudinal com professores, organizamos um grupo de estudo como subprojeto sobre práticas formativas e investigativas em mídia-educação com a intenção de lançar diferentes olhares para a formação de docentes. A intenção era pensar a elaboração de propostas conjuntas sobre a mídia-educação com os educadores da rede municipal que participaram da pesquisa. Alguns aspectos desse percurso foram discutidos em Guntzel et al. (2012).

$\mathrm{Na}$ investigação a respeito do tema multiletramentos e aprendizagens formais e informais, construímos algumas aproximações com a metodologia EAS na escola, que também previa uma proposta piloto de formação com professores, de modo a consolidar diversas possibilidades de parceria e diálogo entre universidade e comunidade, seguindo os pressupostos da pesquisa-formação. A referida proposta de formação piloto buscou apresentar a metodologia EAS e a perspectiva das multiliteracies como aproximação e iniciação. Desse modo, operamos com a metodologia EAS na própria proposta formativa com os professores, que também envolveu a oferta de diversas oficinas em formato de EAS (por exemplo: Mapa conceitual/mental; Dispositivos audiovisuais; Performances e jogos de expressão do teatro do oprimido nos EAS).

Educação \& Formação, Fortaleza, v. 2, n. 6, p. 87-100, set./dez. 2017

DOI: http://dx.doi.org/10.25053/edufor.v2i6.2377

http://seer.uece.br/redufor 
Nesse percurso, sugerimos aos professores que desenvolvessem uma experimentação didática em suas escolas com o que haviam estudado e entendido sobre a metodologia EAS, para que pudessem aprender fazendo, resolvendo problemas e refletindo. Tais experiências foram compartilhadas e discutidas no grupo de formação e posteriormente apresentadas em Seminário de Socialização da Pesquisa (FANTIN, 2015a). A proposta de formação evidenciou não apenas a possibilidade de participação e diálogo com o território, mas sobretudo o interesse dos professores em continuar o diálogo, mesmo após o término da pesquisa, apontando a possibilidade de um trabalho em rede (FANTIN, 2016).

\section{ALGUMAS CONSIDERAÇÕES}

Diante de tantos descompassos entre políticas públicas de inserção das tecnologias nas escolas e políticas de formação docente, percebemos que a formação universitária, em geral, não dá conta da aprendizagem necessária a respeito da integração significativa das tecnologias nos processos de ensino-aprendizagem. Com isso, o professor busca suprir tais lacunas de diferentes formas: esforço pessoal com familiares e amigos, cursos de extensão, cursos de especialização e formação permanente ou continuada nos locais de atuação.

Se a pesquisa reativa é insuficiente, é necessário haver um diálogo entre as diferentes possibilidades de formação, no sentido de aprofundar a reflexão e a participação de professores na construção de propostas para a formação. Desse modo, a pesquisa-formação pode se constituir em um espaço de formação-intervenção-reflexão com participação colaborativa de professores, estudantes e pesquisadores. Esse entendimento da prática colaborativa, mais do que uma proposta metodológica que revela o princípio educativo da pesquisa, é fundamental não só para a análise e a elaboração de propostas de formação em mídia-educação, como também para a construção de subsídios à reflexão teórica e prática sobre novas metodologias de ensino.

Os diferentes olhares, os diversos níveis de interação e as interfaces da pesquisa-formação propiciam uma experiência imersiva de professores e pesquisadores nos processos formativos. A reflexão conjunta que envolve pesquisadores e professores participantes da pesquisa pode ser uma interessante possibilidade de diálogo com vistas a pensar diferentes pistas para a formação. 
Nesse percurso, elencamos distintas propostas formativas fundamentadas em consistentes referenciais teóricos e em uma metodologia de trabalho participativa, que envolveu atividades de: leitura prévia de textos selecionados para subsidiar a discussão, tarefas compartilhadas, trabalhos de produção individual e coletiva, socialização de experiências e atividades on-line - construção de um blog coletivo e produções colaborativas e compartilhadas em rede - que se intercalavam com encontros presenciais. O foco das discussões buscava relacionar as questões observadas na dimensão da prática pedagógica. Como avaliação e reflexão dos percursos, o protagonismo dos professores evidenciou-se tanto na participação e apresentação de tal experiência num Seminário de Socialização da Pesquisa em Mídia-Educação (GUNTZEL et al., 2012) como no Seminário Multideas (FANTIN, 2015a), todos realizados na universidade pesquisada.

Por fim, destacamos que a relação entre ensino e pesquisa-formação adotada na perspectiva deste trabalho considerou a formação cultural, a mídia-educação, as multiliteracies e a metodologia EAS como possibilidades mediadoras da cultura. Nas experiências desencadeadas no processo de ensinar e aprender, tanto no curso de Pedagogia quanto no contexto das referidas pesquisas, deparamo-nos com desafios, estranhamentos e curiosidades necessários para descobrir outros modos de entender o sujeito em seu processo formativo.

Nessa construção, os saberes e fazeres de professores e pesquisadores que estão em jogo se transformaram em experiências de ensino-aprendizagem que naquele momento se revelaram em condição de inteligibilidade de mundo. Um mundo que cada vez mais solicita outras formas de participação na escola, na sociedade e na cultura contemporânea e que demanda um trabalho de pesquisa-formação com professores que não seja apenas voltado às habilidades operativas e instrumentais, mas à construção de competências de reflexão crítica sobre os conteúdos e seus processos e também de produção e compartilhamento no contexto da cultura digital.

\section{REFERÊNCIAS}

BELLONI, M. L. Crianças e mídias no Brasil: cenários de mudança. São Paulo: Papirus, 2010.

Educação \& Formação, Fortaleza, v. 2, n. 6, p. 87-100, set./dez. 2017

DOI: http://dx.doi.org/10.25053/edufor.v2i6.2377

http://seer.uece.br/redufor 
BONILLA, M. H.; FANTIN, M. Olhares sobre a prática pedagógica com o Projeto UCA. In: QUARTIERO, E. M.; BONILLA, M. H.; FANTIN, M. (Org.). Projeto UCA: entusiasmos e desencantos de uma política pública. Salvador: UFBA, 2015. p. 99-145.

BRUNER, J. La cultura dell'educazione. Nuove orizzonti per la scuola. Milano: Feltrinelli, 2002.

BRUNER, J. Realidade mental, mundos possíveis. Porto Alegre: Artes Médicas, 1998.

BUCKINGHAM, D. Media education: literacy, learning and contemporary culture. Cambridge: Polity, 2005.

BUCKINGHAM, D. Youth, identity and digital media. Cambridge: MIT, 2008.

COPE, B.; KALANTZIS, M. (Ed.). Multiliteracies: Literacy learning and the design of social futures. New York: Routledge, 2000.

DAMIANO, E. Didattica come teoria della mediazione. Milano: Franco Angeli, 2013.

DURAND, M.; SAURY, J.; VEYRUNES, P. Relações fecundas entre pesquisa e formação docente: elementos para um programa. Cadernos de Pesquisa, São Paulo, v. 35, n. 125, p. 37-62, 2005.

FANTIN, M. (Org.). I Seminário Multideas. Florianópolis: Seminário Multideas, 2015a.

FANTIN, M. Dimensões da formação cultural e da mídia-educação na Pedagogia. EntreVer, Florianópolis, v. 2, p. 264-280, 2012.

FANTIN, M. Mídia-educação: olhares, conceitos e experiências Brasil e Itália. Florianópolis: Cidade Futura, 2006.

FANTIN, M. Nativos e imigrantes digitais em questão: crianças e competências midiáticas na escola. Revista Passagens, Fortaleza, v. 7, p. 5-26, 2016.

FANTIN, M. Novos paradigmas da didática e a proposta metodológica dos Episódios de Aprendizagem Situada, EAS. Educação e Realidade, Porto Alegre, v. 40, p. 443-464, 2015b.

FANTIN, M. Perspectives on media literacy, digital literacy and information literacy. International Journal of Digital Literacy and Digital Competence, v. 1, n. 4, p. 10-16, 2010.

FANTIN, M.; GIRARDELLO, G. Diante do abismo digital: mídia-educação e mediações culturais. Perspectiva, Florianópolis, v. 27, p. 69-96, 2009.

FANTIN, M.; QUARTIERO, E. M. Práticas educativas e culturais de estudantes e suas percepções sobre as tecnologias móveis na escola. Perspectiva, Florianópolis, v. 33, n. 2, p. 523-544, 2015.

FREINET, C. La scuola del fare. Bergamo: Junior, 2002.

Educação \& Formação, Fortaleza, v. 2, n. 6, p. 87-100, set./dez. 2017

DOI: http://dx.doi.org/10.25053/edufor.v2i6.2377

http://seer.uece.br/redufor 
GUNTZEL, C. et al. Práticas investigativas e formativas em mídia-educação: três olhares para a formação do professor. In: FANTIN, M.; RIVOLTELLA, P. C. (Org.). Escola e cultura digital. Campinas: Papirus, 2012. p. 309-346.

LIAW, S.-S.; HATALA, M.; HUANG, H.-M. Investigating acceptance toward mobile learning to assist individual knowledge management. Computers \& Education, v. 54, p. 446-454, 2010.

LONGAREZI, A. M.; SILVA, J. L. Interface entre pesquisa e formação de professores: delimitando o conceito de pesquisa-formação. In: EDUCERE, 8., 2008, Curitiba. Anais... Curitiba: Champagnat: Araucária, 2008. p. 4048-4061.

NERI, M. Mapa da inclusão digital. Rio de Janeiro: FGV, 2013.

PACHLER, N. (Ed.). Mobile learning: Towards a research agend. London: WLE Centre, 2007.

QUARTIERO, E. M.; FANTIN, M. Education-research in school: Places and author ships in question. Research on Education and Media, v. 2, p. 35-46, 2014.

RIVOLTELLA, P. C. Didattica inclusiva con gli EAS. Brescia: La Scuola, 2015.

RIVOLTELLA, P. C. Fare didattica con gli EAS. Brescia: La Scuola, 2013.

RIVOLTELLA, P. C. La previsione. Brescia: La Scuola, 2104.

SANTAELLA, L. A aprendizagem ubíqua na educação aberta. Tempos e Espaços, Alagoas, n. 14, p. 15-22, 2014. 